\title{
RELACIÓN ENTRE EL ESTRÉS Y LAS BACTERIAS ENTOMOPATÓGENAS Pantoea (Erwinia) agglomerans (herbicola) Y Bacillus cereus EN JOBOTOS (Col: Melolonthidae) (Phyllophaga spp., Anomala spp. Y Cyclocephala spp.), EN COSTA RICA1
}

\author{
Edgar Vargas $^{2}$, Giselle Abarca ${ }^{3}$
}

\begin{abstract}
RESUMEN
Relación entre el estrés y las bacterias entomopatógenas Pantoea (Erwinia) agglomerans (herbicola) y Bacillus cereus en jobotos (Col: Melolonthidae) (Phyllophaga spp., Anomala spp. y Cyclocephala spp.), en Costa Rica. Se determinaron las concentraciones de las unidades formadoras de colonias (UFC) de las bacterias entomopatógenas Pantoea agglomerans y Bacillus cereus, en los estados de huevo, larvas, pupa y adulto, de algunas especies de jobotos (Phyllophaga y Cyclocephala), de importancia agrícola, colectadas en cinco agroecosistemas de Costa Rica. Las larvas $\mathrm{L}_{3}$ y $\mathrm{L}_{2}$ de Phyllophaga elenans, colectadas en las regiones geográficas estudiadas, fueron portadoras en alto grado de Pantoea agglomerans y de Bacillus cereus. Los estadios $\mathrm{L}_{3}$ y $\mathrm{L}_{2}$ de Phyllophaga obsoleta, Phyllophaga menetriesi, Cyclocephala sanguinicollis y Cyclocephala castaniella, procedentes del Valle Central y Pacífico Central, fueron portadoras de Pantoea agglomerans y Bacillus cereus. Entre un $60 \%$ y $90 \%$ de las larvas, en todas las especies de jobotos estudiadas, Pantoea agglomerans presentó las mayores concentraciones de UFC, mientras que Bacillus cereus presentó las más bajas concentraciones. En los estados de huevo, pupa y adulto Phyllophaga presentó una mortalidad ocasionada por la infección Pantoea agglomerans en un $62 \%, 80 \%$ y $22,5 \%$ respectivamente. Se discute además, la posible interacción antagónica entre Pantoea agglomerans y Bacillus cereus. En general, en este estudio se observó que factores como la luz y manipulación de los instares larvales fueron los principales causantes de estrés en estos escarábidos.
\end{abstract}

\begin{abstract}
Relationship between stress and development of entomopathogenic bacteria Pantoea (Erwinia) agglomerans (herbicola), and Bacillus cereus in several species of the white grub complex (Col: Melolonthidae) (Phyllophaga spp., Anomala spp. and Cyclocephala spp.) in Costa Rica. Concentrations of Colony Forming Units (CFU) were determined for two entomopathogenic bacteria (Pantoea agglomerans and Bacillus cereus), at the egg, larval, pupal, and adult stages of agriculturally important Phyllophaga and Cyclocephala white grubs, which were collected in five agroecosystems in Costa Rica. $\mathrm{L}_{2}$ and $\mathrm{L}_{3}$ larvae of Phyllophaga elenans collected in all regions where the study was conducted were extensive carriers of Pantoea agglomerans and Bacillus cereu. $\mathrm{L}_{2}$ and $\mathrm{L}_{3}$ larvae of Phyllophaga obsoleta, Phyllophaga menetriesi, Cyclocephala sanguinicollis and Cyclocephala castaniella found in the Central Valley and Central Pacific regions were carriers of Pantoea agglomerans and Bacillus cereus bacteria. In $60 \%$ to $90 \%$ of larvae in all white grub varieties studied, Pantoea agglomerans showed greater concentrations of CFU than Bacillus cereu, which showed the lowest CFU concentration. Egg, pupal, and adult mortality in all Phyllophaga species was due to Pantoea agglomerans in $62 \%, 80 \%$ and $22.5 \%$ of the cases, respectively. A possible antagonistic interaction between Pantoea agglomerans and Bacillus cereus is also discussed. In general, it was noted that light and larval manipulation were the main stress factors affecting these scarabids.
\end{abstract}

\section{INTRODUCCION}

Las larvas de algunas especies de escarábidos que pertenecen a los géneros Phyllophaga, Anomala y Cyclo- cephala, se han convertido en el centro de atención de muchos productores e investigadores, debido a que estos insectos les han ocasionado reducciones económicas en los rendimientos a una amplia gama de cultivos.

1 Trabajo financiado por el CIPROC, Facultad de Agronomía, Universidad de Costa Rica. San José, Costa Rica.

2 Laboratorio de Fitopatología, Escuela de Fitotecnia, Facultad de Agronomía, Universidad de Costa Rica.

3 Laboratorio de Entomología, Escuela de Fitotecnia, Facultad de Agronomía, Universidad de Costa Rica. 
En la naturaleza se ha observado que los jobotos sufren enfermedades ocasionadas por otros organismos, desde hace muchas décadas. Entre estos organismos se han mencionado a las bacterias, las que han sido agrupadas en formadoras y no formadoras de esporas (Tanada, 1963).

Se ha informado sobre la capacidad limitada de sobrevivencia de bacterias no formadoras de esporas fuera de su hospedero, ya que rápidamente son destruidas por un efecto de desecación o por la luz solar (Tanada, 1963). Sin embargo, se ha indicado que pueden sobrevivir por periodos largos bajo ciertas condiciones, tales como suelos húmedos, cadáveres y heces. También se ha señalado que estas bacterias entomopatógenas son transmitidas a sus hospederos generalmente porque los mismos se alimentan de material contaminado con el entomopatógeno, o a través de canibalismo.

Isakova, 1954, citado por Tanada (1963) observó que cuando fueron multiplicadas al mismo tiempo tres especies de bacterias en un medio líquido, éstas resultaron más patogénicas a insectos que cuando fueron reproducidas individualmente.

Steinhaus, 1958, 59, citado por Tanada (1963), señaló que las infecciones bacterianas de insectos o infecciones latentes, frecuentemente han sido causadas por las mismas especies que habitan en el tracto digestivo de los insectos sanos, y que estas infecciones fueron manifestadas cuando un estrés provocó algún desorden en el mecanismo homeostático, lo que condujo a la multiplicación anormal de las bacterias en el tracto digestivo; aunado a esto se incrementó el estrés y permitió que las bacterias invadieran el hemocelo, provocando la septicemia en la larva (Bucher, 1981, citado por Shannon, 1994).

El estrés ha sido referido como el estado manifestado en un síndrome o cambios corporales causado por alguna fuerza, condición o circunstancia en o sobre un insecto, o sobre uno de los sistemas fisiológicos o anatómicos, que predisponen al insecto para que se le desarrolle una enfermedad infecciosa latente. El estresor es cualquier estímulo o sucesión de estímulos, que tiendan a romper la homeostasis de las larvas, dependiendo de las circunstancias y del nivel de intensidad (Steinhaus, 1958a, 1960b, citado por Tanada, 1963).

Vargas y Abarca (1991), informaron por primera vez sobre la patogenicidad de Erwinia y Bacillus cereus en algunas especies de Phyllophaga, en Costa Rica. Ambas bacterias fueron identificadas posteriormente en el Laboratorio de Fitopatología, de la Universidad de Wisconsin; en el caso de Erwinia como E. agglomerans, la cual ha sido recientemente reclasificada como Pantoea agglomerans por Baird et al, pero para una ra- za patógena en algodón (Graham y Hodgkiss, 1967; Baird, R.E. y Gitaitis, R.D., 1997).

Debido al potencial de los entomopatógenos latentes como medida de combate biológico promisorio para estos escarábidos, y a la carencia de información sobre la distribución de estos organimos en los agroecosistemas, y el grado en que estos patógenos son portados por las especies de jobotos, se decidió estudiar en algunas especies de importancia agrícola del complejo de jobotos de Costa Rica, a los entomopatógenos nativos de estos insectos en agroecosistemas diferentes, y determinar el grado en que estos organismos son portados por las especies de jobotos, así como establecer las relaciones entre las epizootias causadas por estos patógenos y los estados del ciclo de vida de estos coleópteros.

\section{MATERIALES Y MÉTODOS}

En los sitios ubicados en: Fraijanes, Santa Eulalia, San Isidro (Alajuela); Potrero Cerrado (Cartago); Filadelfia (Guanacaste); Miramar (Puntarenas) y Pérez Zeledón (San José); fueron colectadas larvas del complejo de jobotos en los estadios $\mathrm{L}_{1}, \mathrm{~L}_{2} \mathrm{y} \mathrm{L}_{3}$, colocadas en envases plásticos individualmente y trasladadas al laboratorio para los estudios correspondientes. Se utilizaron un promedio de 150 larvas por muestreo, por cada sitio de estudio. El recuento de larvas vivas se efectuó al ingreso de estas poblaciones al laboratorio y después cada 24 horas, durante todo el periodo larval, así como en los periodos de pupas y adultos.

Una parte de las larvas $\mathrm{L}_{3}$ de las poblaciones colectadas en las zonas de estudio, fueron preservadas en KAAD (etanol, ácido acético glacial, dioxano y kerosene en una proporción 7:2:2:1, respectivamente) durante ocho horas. Luego, fueron colocadas en etanol al $70 \% \mathrm{v} / \mathrm{v}$, para su posterior identificación. El raster y las estructuras taxonómicas observadas en el estadio $\mathrm{L}_{3}$ de las larvas y propuestas por King (1985) y Morón (1986, 1988) fueron la base para la identificación al nivel de género y especie. En las poblaciones $\mathrm{L}_{1}, \mathrm{~L}_{2}$ y la otra parte de las larvas $\mathrm{L}_{3}$ fueron estudiados los organismos patógenos de estos estadios, así como en las pupas y adultos que fueron criados en el laboratorio.

\section{Aislamientos de bacterias}

Las larvas de estos insectos fueron colectadas y colocadas con precaución en bandejas plásticas divididas en celdas de 4,8 mm X $3 \mathrm{~mm}$ X 3,5 mm, con el fin de disminuir al máximo los efectos adversos que ocasionan estrés a estos escarábidos como son el manipuleo y la luz. Las larvas $\mathrm{L}_{2}$ y $\mathrm{L}_{3}$ fueron sumergidas en un recipiente de vidrio con agua a punto de ebullición 
durante un minuto, luego fueron flameadas en alcohol de $95 \% \mathrm{v} / \mathrm{v}$, con el fin de finiquitar la limpieza, posteriormente con la ayuda de un bisturí esterilizado fue separada la cabeza del cuerpo, luego éste último (tórax y abdomen) fue macerado en $5 \mathrm{ml}$ de agua destilada estéril, en un mortero previamente esterilizado. Del líquido obtenido se rayaron platos con medio de cultivo, basado en agar, papa, dextrosa (PDA), y se incubaron a $26^{\circ} \mathrm{C}$ durante 72 horas. Se emplearon cuatro repeticiones de platos por larva.

La identificación de las bacterias en cada plato petri, se basó en las características morfológicas de las colonias, y con la ayuda de un estereoscopio con luz transmitida por abajo, fue observada la refringencia y comparada con aislamientos identificados previamente. La población de unidades formadoras de colonias (U.F.C.) fue estimada mediante una escala visual que indicaron las concentraciones bajas (1-10 U.F.C.), medias (10-50 U.F.C.) y altas (+50 U.F.C.) por plato petri, las cuales fueron determinadas en estudios realizados por Vargas y Abarca (1991).

\section{RESULTADOS Y DISCUSIÓN}

En la zona de Fraijanes, los jobotos fueron identificados como Phyllophaga obsoleta, Phyllophaga menetriesi, Anomala granulipyga, Cyclocephala castaniella y Cyclocephala sanguinicollis. Estas especies se encontraron ocasionando pérdidas económicas principalmente en fresa (Fragaria anannas) y pasto kikuyo (Pennisetum purpureum) (Abarca y Quesada, 1997).
Las larvas en los estadios $\mathrm{L}_{2} \mathrm{y} \mathrm{L}_{3}$ de las especies de jobotos en esta zona de estudio, fueron altamente portadoras de la bacteria $P$. agglomerans cuyo porcentaje de concentración de bacteria por larva varió entre $60 \%$ y $75 \%$, mientras que los mayores porcentajes de $B$. cereus fueron bajos en concentración por larva (variaron entre $13 \%$ y $24 \%$ ). Sin embargo, las larvas fueron portadoras de las dos bacterias como se observa en el Cuadro 1.

En Potrero Cerrado, las larvas $\mathrm{L}_{3}$ de las especies de Phyllophaga, fueron altamente portadoras de $P$. agglomerans, principalmente en bajas y altas concentraciones, mientras que $B$. cereus se presentó en bajas concentraciones (Cuadro 1).

Los jobotos asociados a la caña de azúcar (Saccharum officinarum) pertenecen a la especie predominante P. elenans en las zonas de Filadelfia, Miramar y Pérez Zeledón, de las Provincias de Guanacaste, Puntarenas y San José respectivamente (Cuadro 2). En Miramar la incidencia de otras especies de estos escarábidos fueron observadas en el siguiente orden descendiente: P. menetriesi, Anomala spp., P. hondura y P. dasypoda; entre tanto en Pérez Zeledón se encontró únicamente Anomala spp. (Cuadro 2).

Las larvas de P. elenans en el estadio $\mathrm{L}_{3}$, procedentes de la zonas de estudio, en general fueron portadoras en alto grado de $P$. agglomerans, donde los mayores porcentqjes ocurrieron en las concentraciones de bajas a medias, en cambio, $B$. cereus mostró los mayores porcentajes en las concentraciones bajas (Cuadro 2).

Cuadro 1. Especies $\mathrm{L}_{3}$ del complejo de jobotos (Col: Scarabaeidae) (Phyllophaga, Anomala y Cyclocephala) portadoras de Pantoea agglomerans y Bacillus cereus, según la concentración de UFC, en dos cultivos en Alajuela y Cartago, Costa Rica.

\begin{tabular}{|c|c|c|c|c|c|c|c|c|}
\hline \multirow[t]{3}{*}{ Localidad } & \multirow[t]{3}{*}{ Cultivo } & \multirow[t]{3}{*}{ Género y especie } & \multicolumn{6}{|c|}{ Larvas $L_{3}$ portadoras $(\%)$} \\
\hline & & & \multicolumn{3}{|c|}{ P. agglomerans } & \multicolumn{3}{|c|}{ Bacillus cereus } \\
\hline & & & $\mathbf{A}$ & $\mathbf{M}$ & B & $\mathbf{A}$ & $\mathbf{M}$ & B \\
\hline \multirow[t]{2}{*}{ Fraijanes } & Fragaria anannas & $\begin{array}{l}\text { Phyllophaga obsoleta } \\
\text { Phyllophaga menetriesi }\end{array}$ & 17,5 & 51,7 & 10,8 & 4,1 & 12,7 & 24,3 \\
\hline & Pennisetum clandestinum & $\begin{array}{l}\text { Cyclocephala sanguinicollis } \\
\text { Cyclocephala castaniella }\end{array}$ & 7,4 & 51,8 & 6,9 & 0,0 & 0,0 & 13,7 \\
\hline Potrero Cerrado & Pennisetum clandestinum & $\begin{array}{l}\text { Phyllophaga obsoleta } \\
\text { Phyllophaga menetriesi }\end{array}$ & 33,3 & 11,1 & 44,4 & 0,0 & 0,0 & 100 \\
\hline
\end{tabular}

$\mathrm{A}=$ Concentración alta de colonias por larvas.

$\mathrm{M}=$ Concentración media de colonias por larva.

$\mathrm{B}=$ Concentración baja de colonias por larva.

$\mathrm{UFC}=$ Unidades Formadoras de Colonias. 
Cuadro 2. Larvas $\mathrm{L}_{3}$ y $\mathrm{L}_{2}$ del complejo de jobotos (Col: Scarabaeidae) (Phyllophaga, Anomola y Cyclocephala) portadoras de Pantoea (Erwinia) agglomerans y Bacillus cereus, según la concentración de U.F.C. en caña de azúcar (Saccharum officinarum), en algunas provincias de Costa Rica.

\begin{tabular}{|c|c|c|c|c|c|c|c|}
\hline \multirow[t]{3}{*}{ Localidad } & \multirow[t]{3}{*}{ Género y especies } & \multicolumn{6}{|c|}{ Larvas $L_{3}$ y $\mathbf{L}_{2}$ portadoras $(\%)$} \\
\hline & & \multicolumn{3}{|c|}{ P. agglomerans } & \multicolumn{3}{|c|}{ Bacillus cereus } \\
\hline & & $\mathbf{A}$ & M & B & $\mathbf{A}$ & $\mathbf{M}$ & $\mathbf{B}$ \\
\hline \multirow[t]{4}{*}{ Filadelfia, Guanacaste } & \multirow[t]{4}{*}{ Phyllophaga elenans } & 5,0 & 10,0 & 85,9 & 0 & 10 & 90 \\
\hline & & 38,0 & 28,6 & 28,6 & 0 & 5 & 95 \\
\hline & & 16,6 & 8,3 & 70,8 & 0 & 10 & 90 \\
\hline & & 35,0 & 20,0 & 40,0 & 0 & 0 . & 100 \\
\hline \multirow[t]{4}{*}{ Miramar, Puntarenas } & \multirow[t]{4}{*}{ Phyllophaga elenans } & 23,3 & 53,3 & 13,3 & 0 & 0 & 100 \\
\hline & & 12,5 & 20,8 & 58,3 & 0 & 10 & 90 \\
\hline & & 17,7 & 29,4 & 52,6 & 0 & 0 & 100 \\
\hline & & 12,5 & 0,0 & 81,3 & 0 & 0 & 100 \\
\hline \multirow[t]{3}{*}{ Buenos Aires, San José } & \multirow[t]{3}{*}{ Phyllophaga elenans } & 41,2 & 29,4 & 17,6 & 0 & 0 & 100 \\
\hline & & 20,0 & 40,0 & 35,0 & 0 & 0 & 100 \\
\hline & & 9,0 & 9,0 & 45,0 & 0 & 0 & 100 \\
\hline Atenas, Alajuela & Phyllophaga menetriesi & 62,5 & 0,0 & 25,0 & 0 & 0 & 100 \\
\hline San Ramón, Alajuela & Cyclocephala lunulata & 49,3 & 7,3 & 33,7 & 0 & 0 & 100 \\
\hline Carrizal, Puntarenas & Phyllophaga obsoleta & 7,2 & 61,8 & 8,3 & 0 & 0 & 22,5 \\
\hline
\end{tabular}

$\mathrm{A}=$ Concentración alta de colonias por larvas.

$\mathrm{B}=$ Concentrración baja de colonias por larvas.

$\mathrm{M}=$ Concentración media de colonias por larvas.

UFC $=$ Unidades Formadoras de Colonias.

En otras regiones cañeras como Carrizal de Esparza (Puntarenas) y San Ramón, Santa Eulalia, Atenas (Alajuela), las larvas en el estadio $\mathrm{L}_{3}$ fueron identificadas como P. obsoleta, C. lunulata y P. menetriesi respectivamente (Cuadro 2).

Las larvas de $P$. obsoleta, $C$. lunulata y P. menetriesi resultaron altamente portadoras de P. agglomerans cuyos mayores porcentajes fueron observados en altas y bajas concentraciones de bacteria por larva; entre tanto el B. cereus fue encontrado en mayor porcentaje a bajas concentraciones (Cuadro 2).

En este estudio, las larvas del complejo de jobotos mostraron que aún en apariencia sana, fueron altamente portadoras de $P$. agglomerans y B. cereus las cuales coexistieron dentro de la larva; esta asociación de bacterias fue constante para todas las especies estudiadas, donde $P$. agglomerans presentó los mayores porcentajes de bacteria por larva comparado con $B$. cereus (Cuadros 1 y 2). También se observó que la concentración de P. agglomerans en las larvas varió entre las localidades y los cultivos, pero no entre géneros o especies. Esto podría estar relacionado con las concentraciones más altas de la bacteria en la rizosfera y con mayor ingestión por la larva al alimentarse de las raíces o de n,ateria orgánica. Además, los datos obtenidos revelaron una relación estrecha entre estas bacterias y algunas especies rizófagas de Phyllophaga, Anomala y Cyclocephala en los estadios $\mathrm{L}_{2} \mathrm{y} \mathrm{L}_{3}$. De hecho, esta relación y el grado de patogenecidad de P. agglomerans y B. cereus sobre larvas de Phyllophaga, fue informado por primera vez por Vargas y Abarca (1991).

La concentración de $P$. agglomerans en las larvas, varió entre la localidad y cultivo pero no entre géneros o especies.

Otro aspecto observado fue que cuando los jobotos fueron sometidos a condiciones de estrés tales como exposición a la luz, manipuleo y confinados a espacios reducidos, manifestaron los síntomas de enegrecimiento de los últimos segmentos abdominales, parálisis de la parte posterior del abdomen y pérdida de apetito, ocasionados por la enfermedad causada por $P$. agglomerans con la consecuente muerte de los mismos (Figura 1). Así, las larvas procedentes de Filadelfia mostraron una mortalidad de $20,7 \%, 24 \%$ y $24 \%$ en las larvas $\mathrm{L}_{1}, \mathrm{~L}_{2}$ y $\mathrm{L}_{3}$, respectivamente; las de Miramar, presentaron un $21,5 \%, 13,5 \%$ y $22,4 \%$ de mortalidad en 


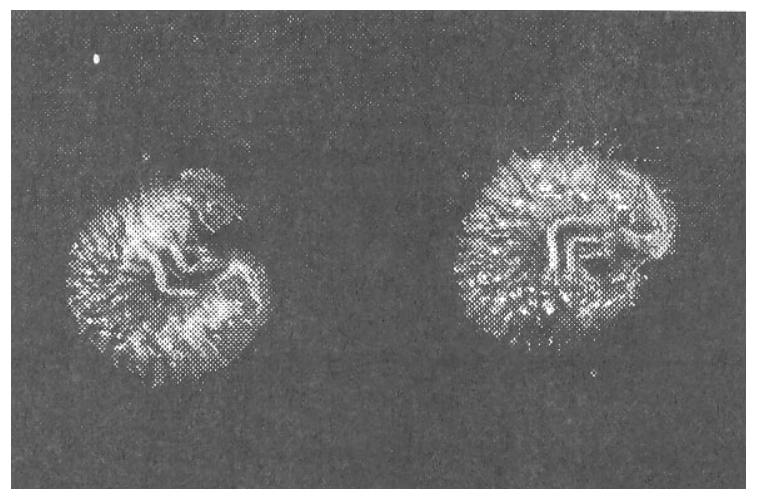

Figura 1. Síntomas de la enfermedad ocasionada por $P$. agglomerans en larvas de jobotos del género Phyllophaga spp. (Col: Melolonthidae).

los estadios $\mathrm{L}_{1}, \mathrm{~L}_{2}$ y $\mathrm{L}_{3}$, respectivamente y en las de Pérez Zeledón se observó una mortalidad de $51 \%, 16 \%$ y $16 \%$ en los estadios $\mathrm{L}_{1}, \mathrm{~L}_{2} \mathrm{y} \mathrm{L}_{3}$, respectivamente (Cuadro 3).

También, fue evidente el dominio de la enfermedad causada por esta bacteria cuando se comparó con el Bacillus. Todo pareciera indicar que al someter ese alto porcentaje de larvas portadoras de las bacterias a condiciones de estrés, el proceso de la enfermedad fue desarrollado por P. agglomerans debido a un posible efecto antagónico de esta bacteria sobre el bacilus. Esto podría ser respaldado con lo afirmado por Isakova, 1954 y citado por Tanada (1963), cuando ha indicado que la virulencia e infectividad de las bacterias de la entomofauna, ha sido asociado con las relaciones sinergísticas o antagónicas que ocurren entre ellas.

P. agglomerans no produce esporas, no obstante es un habitante común del suelo, por esta razón ha sido aislada de larvas de jobotos que se han encontrado en clases de suelo tales como Melanudands, Ustropets y Haplustands (Quesada y Abarca, 1997).

Es posible que las especies de jobotos en los agroecosistemas estudiados adquirieron a estas bacterias por ingestión, ya que en los primeros instares las larvas se alimentaron del suelo, el cual es probable que halla estado contaminado por cadáveres o heces de otras larvas que murieron infectadas por esta bacteria. Esto ha sido reafirmado por Tanada (1963) cuando citó los estudios realizados por White, $1923 \mathrm{~b}$, con respecto a las posibles formas de transmisión y permanecia de estas bacterias en el suelo. Aunado a esto, es probable que las bacterias estudiadas fueron parte de la flora microbiana en la rizosfera, de donde fueron adquiridas por las larvas a través del suelo o de las raíces.

Por otro lado, los huevos no escaparon a las enfermedades ocasionadas por bacterias y hongos. En condiciones de laboratorio, los huevos de P. obsoleta y A. cupricollis murieron por la enfermedad causada por $P$. agglomerans, para un $62 \%$ y $61 \%$, del total de huevos respectivamente (Cuadro 4). Además, Metarrhizum anisoplae provocó la muerte a huevos de P. obsoleta en un 3\% del total de éstos (Cuadro 4). La transmisión de la bacteria a los huevos es posible que fue dada por materia fecal o cadáveres que contaminaron el muscílago externamente, como lo ha informado d'Herelle, 1914, citado por Tanada (1963).

Los estados de pupas también fueron afectados por la enfermedad, así en $P$. obsoleta fue encontrado un $100 \%$ de mortalidad de un total de 15 pupas; mientras que en $P$. elenans fue obtenido un $80 \%$ de mortalidad, de un total de 15 pupas, bajo condiciones controladas. Los síntomas observados fueron un enegrecimiento del cuerpo, que se inició en la parte posterior del abdomen, posteriormente esa coloración oscura avanzó hacia el tórax y luego se presentó la muerte.

Cuadro 3. Relación entre la patogenicidad Pantoea (Erwinia) agglomerans y el estrés por manipuleo en larvas $\mathrm{L}_{1}$, $\mathrm{L}_{2}$ y $\mathrm{L}_{3}$ de Phyllophaga elenans.

\begin{tabular}{|c|c|c|c|c|c|c|c|c|c|c|c|c|c|c|c|}
\hline \multirow[t]{2}{*}{ Localidad } & \multicolumn{5}{|c|}{ Larvas L1 } & \multicolumn{5}{|c|}{ Larvas L2 } & \multicolumn{5}{|c|}{ Larvas L3 } \\
\hline & Total & $\begin{array}{c}\text { Enfer- } \\
\text { mas }\end{array}$ & $(\%)$ & $\begin{array}{c}\text { Muer- } \\
\text { tas }\end{array}$ & $(\%)$ & Total & $\begin{array}{c}\text { Enfer- } \\
\text { mas }\end{array}$ & $(\%)$ & $\begin{array}{c}\text { Muer- } \\
\text { tas }\end{array}$ & $(\%)$ & Total & $\begin{array}{c}\text { Enfer- } \\
\text { mas }\end{array}$ & $(\%)$ & $\begin{array}{c}\text { Muer- } \\
\text { tas }\end{array}$ & $(\%)$ \\
\hline Filadelfia, Guanacaste & 121 & 1 & 0,8 & 17 & 14 & 145 & 1 & 0,7 & 24 & 19,8 & 312 & 1 & 3,2 & 51 & 16,3 \\
\hline Miramar, Puntarenas & 28 & 2 & 7,0 & 4 & 14 & 78 & 2 & 2,6 & 9 & 11,5 & 565 & 18 & 3,2 & 90 & 16,0 \\
\hline Buenos Aires, San José & 82 & 0 & 0,0 & 35 & 43 & 57 & 0 & 0,0 & 7 & 12,3 & 72 & 1 & 1,4 & 10 & 13,9 \\
\hline
\end{tabular}


Cuadro 4. Patogenicidad de P. agglomerans y Metarrhizum sp. sobre huevos de Phyllophaga obsoleta y Anomala cupricollis, en condiciones de campo.

\begin{tabular}{|c|c|c|c|c|c|}
\hline \multirow[t]{2}{*}{ Género y especie } & \multirow{2}{*}{$\begin{array}{c}\mathrm{N}^{\circ} \text { Total } \\
\text { de huevos }\end{array}$} & \multicolumn{2}{|c|}{$\mathrm{N}^{\circ}$ Total de huevos muertos } & \multicolumn{2}{|c|}{ Huevos muertos (\%) } \\
\hline & & P. agglomerans & Metarrhizum sp & P. agglomerans & Metarrhizum sp \\
\hline Phyllophaga obsoleta & 264 & 164 & 8 & $62 \%$ & $3 \%$ \\
\hline Anomala cupricollis & 44 & 27 & 0 & $61 \%$ & --- \\
\hline
\end{tabular}

Los adultos también presentaron la muerte ocasionada por $P$. agglomerans en un $22,5 \%$ de un total de 40 individuos. Los síntomas observados fueron ennegrecimiento de la parte posterior del abdomen y los élitros mal formados, con la muerte como resultado final.

\section{AGRADECIMIENTO}

Los autores agradecen a Rafael Mata y Elizabeth Carazo (Escuela de Fitotecnia, Universidad de Costa Rica) por la revisión de este manuscrito. A la Vicerrectoría de Investigación, de la Universidad de Costa Rica por la cooperación en el desarrollo de este estudio. A Carlos Sáenz y al personal técnico de la Dirección de Investigación y Extensión de la Caña de Azúcar por su colaboración en el suministro de larvas.

\section{LITERATURA CITADA}

ABARCA, G.; QUESADA, M.A. 1997. Especies del complejo de jobotos (Phyllophaga spp., Anomala spp. y $C y$ clocephala spp.), en el Valle Central y Pacífico Seco de Costa Rica. Agronomía Mesoamerica 8(2): 44-53.

ARUGA, H. 1963. Induction of virus infections. In Insect Pathology. An Advanced Treatise. 1970. Ed. Steinhaus, E.A. V.I. Academic Press. New York and London. 2: 519-522.

BAIRD, R.E.; GITAITIS, R.D. 1997. First report of cotton lint rot by Pantoea agglomerans in Georgia (Abtr). Plant Disease 81: 551.

GRAHAM, D.e.; HODGKISS, W. 1967. Idenfity og Gram negative, yellow pigmented, fermentative bacteria iso- lated form plants and animals.Journal Applied Bacteriology. 30: 175-189.

KING, A.B.S. 1984. Biology and identification of white grubs (Phyllophaga) of economic importance in Central America. Tropical Pest Management 30(1): 36-50

KLEIN, M.G.; JACKSON, T.A. Bacterial Diseases of Scarabs. In: Use of Pathogens in Scarab Pest Management. 1992. Ed. Glare y Jackson. Hampshire, England. 43-61 pp.

MORON, M.A. 1988. Las especies de Phyllophaga (Col: Melolonthidae) con mayor importancia agrícola en México. In III Mesa redonda sobre plagas del suelo. Michoacán, México. 81-102 p.

SHANNON, P.J. 1994. Control microbiano de Phyllophaga spp. (Col: Melolonthidae). In Seminario-Taller Centroamericano sobre la Biología y Control de Phyllophaga spp. CATIE, Turrialba, Costa Rica. Memorias. pp. 80-93.

TANADA, Y. 1963. Epizootiology of Infections Diseases. In Insect Pathology and advanced Treatise. 1963. Ed. E. Steinhaus. Academic Press. New York and London. 2: 423-475.

VILLANI, M.G.; KRUEGER, S.R.; NYROP, J.P. 1992. A case study of the impact of the soil environment on Insect pathogens interactions. In Use of pathogens in scarab pest management. Ed. Glare y Jakson. Hampshire, England.

VARGAS, E.; ABARCA, G. 1991. Patogenicidad de Bacillus cereus y Erwinia spp. sobre jobotos del género Phyllophaga spp. (Col: Scarabaeidae). Agronomía Costarricense 15(1/2): 157-162. 